\title{
STRATEGI PENDAMPINGAN PEKERJA SOSIAL PADA PASIEN SKIZOFRENIA DI RUMAH SAKIT JIWA GHRASIA
}

\section{Social Worker Association Strategy In The Scizofrenia Patients In Ghrasia Hospital}

\section{ABSTRAK}

Lailatul Fitri

Pascasarjana UIN Sunan Kalijaga (lailatulfitri62@gmail.com )

Latar Belakang: Penderita gangguan jiwa di Indonesia mencapai lebih dari 28 juta orang, dengan kategori gangguan jiwa ringan 11,6\% dari populasi dan 0,46\% menderita gangguan jiwa berat atau 46 per mil. Berdasarkan Riset Kesehatan Dasar menyatakan 14,1\% penduduk Indonesia mengalami gangguan jiwa dari yang ringan hingga berat, kondisi ini diperberat melalui aneka bencana alam yang terjadi di hampir seluruh wilayah Indonesia. Sedangkan menurut data WHO pada tahun 2016, terdapat sekitar 35 juta orang terkena depresi, 60 juta orang terkena bipolar, 21 juta terkena skizofrenia, serta 47,5 juta terkena dimensia. Salah satu gangguan jiwa dengan klasifikasi berat yaitu skrizofrenia karena penyakit ini memiliki perjalanan yang progresif, cenderung menahun (kronik), eksaserbasif (sering mengalami kekambuhan) serta yang paling banyak diderita, kira-kira $60 \%$ penderita gangguan jiwa menderita gangguan skizofrenia dan $40 \%$ dari total tersebut menderita skizofrenia hebefrenik. Tujuan: Studi ini bertujuan untuk mengetahui berbagai strategi pendampingan pekerja sosial dan mengetahui faktor pendukung dan penghambat dalam melakukan strategi pendamping pekerja sosial terhadap pasien gangguan jiwa di Rumah Sakit Jiwa Grasia, strategi yang digunakan akan mempengaruhi keberhasilan seorang pekerja sosial.

Metode: Penelitian ini menggunakan metode wawancara dan partisipasi langsung dalam strategi pendampingan.

Hasil: Hasil penelitian menunjukkan bahwa strategi yang di gunakan pendamping pekerja sosial yaitu pertama, meningkatkan pengetahuan biopsikososial dan spiritual. Kedua, meningkatkan kesadaran pasien skizofrenia. Ketiga, meningkatkan kemampuan dan keterampilan potensi yang dimiliki oleh pasien skizofrenia.

Kesimpulan :Faktor pendukung dan penghambat dalam strategi pendampingan pekerja sosial terdapat dalam dua aspek yaitu pasien dan keluarga.

Kata Kunci: pasien skizofrenia, pekerja sosial, strategi pendampingan

\section{ABSTRACT}

Backgraund: Patients with mental disorders in Indonesia reached more than 28 million people, with the category of mild mental disorders $11.6 \%$ of the population and $0.46 \%$ suffered severe mental disorders or 46 per mile. Based on basic health research, 14.1\% of Indonesians suffer from mild to severe mental disorders, this condition is exacting through various natural disasters occurring in almost all parts of Indonesia. According to WHO data in 2016, there were about 35 million people affected by depression, 60 million people were affected by bipolar, 21 million in schizophrenia, as well as 47.5 million subjected to Dimensia. One of the disorders of the soul with a weight classification is skrizofrenia because the disease has a progressive journey, tends to be chronic (chronicle), exacerbation (often experiencing recurrence) and the most suffered, about $60 \%$ sufferers Mental disorders suffer from schizophrenia disorders and $40 \%$ of those total suffer from schizophrenia hebefrenic. 
Aim : The study aims to determine the strategy of mentoring social workers and to know the supporting factors and barriers in conducting a social worker strategy for mental disorders patients at the Grasia Psychiatric Hospital, a strategy Will affect the success of a social worker.

Method: The research uses methods of interviews and direct participation in mentoring strategies.

Results: The results showed that the strategy used by the social worker companion was the first, increasing the knowledge (biopsychosocial) and spiritual. Secondly, it enhances the patient's ability of schizophrenia patients. Third, improve the abilities and skills of patients with schizophrenia patients.

Conclusion : Supporting factors and barriers in the strategy of mentoring social workers are in two aspects, namely patients and families.

Keywords: schizophrenia patients, social workers, mentoring strategies

\section{PENDAHULUAN}

Kesehatan jiwa masih menjadi salah satu permasalahan yang signifikan di Indonesia. Sehat menurut World Health Organization (WHO) pada ketetapannya di tahun 1984 bahwa sehat merupakan kondisi tubuh yang fungsinya tidak terganggu baik secara mental maupun rohani manusia, dalam lingkup psikologi disebut "bio-psiko-sosio-spiritual". (Kholil Rochman, 2018) Berdasarkan pengertian diatas dapat disimpulkan bahwa kesehatan jiwa yaitu apabila individu mampu mengerti dan mengetahui apa saja potensi yang dimiliki dirinya, baik dari segi kelebihan dan kelemahan yang dimilikinya, sehingga individu tersebut mampu mengatasi masalah dalam kehidupan yang dijalaninya. Sedangkan, gangguan jiwa adalah orang yang mengalami gangguan dalam pikiran, perilaku, dan perasaan yang termanifestasi dalam bentuk sekumpulan gejala atau perubahan perilaku yang bermakna, serta dapat menimbulkan penderitaan dan hambatan dalam menjalankan fungsi orang sebagai manusia.(Undang-Undang, 2014)

Menurut data dari Departemen Kesehatan RI tahun 2007, total jumlah penderita gangguan jiwa di Indonesia mencapai lebih dari 28 juta orang, dengan kategori gangguan jiwa ringan 11,6\% dari populasi dan 0,46\% menderita gangguan jiwa berat atau 46 per mil. Berdasarkan Riset Kesehatan Dasar menyatakan 14,1\% penduduk Indonesia mengalami gangguan jiwa dari yang ringan hingga berat, kondisi ini diperberat melalui aneka bencana alam yang terjadi di hampir seluruh wilayah Indonesia.(Badan Penelitian dan Pengembangan Depkes RI, 2007) Sedangkan menurut data WHO pada tahun 2016, terdapat sekitar 35 juta orang terkena depresi, 60 juta orang terkena bipolar, 21 juta terkena skizofrenia, serta 47,5 juta terkena dimensia. Di Indonesia, terdapat berbagai faktor biologis, psikologis dan sosial dengan keanekaragaman penduduk, maka jumlah 
kasus gangguan jiwa terus bertambah yang berdampak pada penambahan beban negara dan penurunan produktivitas manusia untuk jangka panjang.(DEPKES, t.t.) Berdasarkan data diatas terdapat jumlah penderita gangguan jiwa di Indonesia mengalami peningkatan setiap tahunnya sehingga dibutuhan perhatian dari pemerintah agar pelayanan bagi penderita gangguan jiwa ini bisa lebih baik.

Adapun beberapa klasifikasi dari gangguan jiwa diantaranya yaitu gangguan mental organic, simtomatik, skizofrenia, gangguan skizotipal, gangguan waham, gangguan suasana perasaan (mood/afesktif), gangguan neurotik, gangguan somatoform, gangguan stress.(Rusdi Maslim, 2001)

Hawari (2009) menyatakan bahwa salah satu gangguan jiwa dengan klasifikasi berat yaitu skrizofrenia karena penyakit ini memiliki perjalanan yang progresif, cenderung menahun (kronik), eksaserbasif (sering mengalami kekambuhan) serta yang paling banyak diderita, kira-kira 60\% penderita gangguan jiwa menderita gangguan skizofrenia dan $40 \%$ dari total tersebut menderita skizofrenia hebefrenik.(Hawari, 2009, hlm. 10) Skizofrenia merupakan gangguan psikiatrik yang ditandai dengan disorganisasi pola pikir yang signifikan dan dimanifestasikan dengan masalah komunikasi dan kognisi; gangguan persepsi terhadap realitas yang dimanifestasikan dengan halusinasi dan waham; dan terkadang penurunan fungsi yang signifikan.(Ballard, Kennedy, \& O’Brien, 2014) Gejala skizofrenia muncul pada usia 15-25 tahun lebih banyak ditemukan pada laki-laki dibandingkan pada perempuan.(Ashturkar \& Dixit, 2013, hlm. 65-69)

Berdasarkan kriteria dari Diagnostic and Statistical Manual of Mental Disorders IV - Text Revision V (DSM-IV-TR V), diagnosis skizofrenia terkonfirmasi apabila memiliki dua atau lebih karakteristik dan gejala, salah satu gejalanya adalah delusi/ waham. Waham merupakan kepercayaan yang jelas salah dan mengindikasikan suatu keabnormalan pada isi pikir individu.(Chandra Kiran and Suprakash Chaudhury, 2009, hlm. 3) Gangguan pikir umumnya dikenali dari pembicaraan dan tulisan yang tidak rasional. Hal ini dapat berdampak pada ketidakmampuan individu untuk berkomunikasi dengan baik dan melakukan aktivitas dan tugastugas.(Gelder, Gath, \& Mayou, 1989, hlm. 9-15) Waham yang tidak ditindaklajuti mungkin bisa jadi berbahaya dalam berbagai macam hal, waham tidak hanya menyebabkan stres psikologis dan kecemasan tetapi juga konsekuensi berbahaya dalam kehidupan dirinya dan orang disekitar mereka.(Paolini, Moretti, \& Compton, 2016, hlm. 10) 
Dalam penelitian ini menunjukkan bahwa pasien skizofrenia dapat dikategorikan ke dalam penyandang masalah kesejahteraan sosial, karena pasien skizofrenia mengalami hambatan, kesulitan atau gangguan dalam bersosialisasi. Hal ini menyebabkan tidak terlaksananya fungsi sosial pada pasien skizofrenia sehingga tidak mampu menjalin hubungan yang serasi dan kreatif antara dirinya sendiri, keluarga dan masyarakat di lingkungan sekitarnya, akhirnya, pasien skizofrenia tidak dapat terpenuhi kebutuhan hidupnya (jasmani, rohani dan sosial) secara utuh. Pasien skizofrenia membutuhkan bantuan secara sosial dan rohani agar dapat menjalankan keberfungsian sosialnya, sehingga dibutuhkan pendamping dalam menjalankan keberfungsian sosial klien tersebut yaitu pekerja sosial medis yang biasanya berada di rumah sakit jiwa dan rumah sakit umum. Menurut Barker pekerja sosial medis adalah sebagai berikut: (Robert L. Barker, 1995)

"the sosial work practice that occurs in hospital and others health care setting to facilitate good health, prevent illness, and aid physically patients and their families to resolve the social and psychological problem related to the illness".

Berdasarkan pengertian di atas pekerja sosial medis dapat disimpulkan bahwa ada lima unsur prinsip pokok yaitu: pertama, pekerja sosial medis merupakan praktik pekerja sosial. Hal ini menunjukkan bahwa keterlibatan pekerja sosial di bidang medis terutama untuk melaksanakan intervensi penyembuhan terhadap penyakit pasien sesuai dengan domain pekerja sosial. Kedua, praktik pelayanan pekerja sosial medis tidak hanya dilakukan di rumah sakit saja, akan tetapi juga di tempat- tempat yang lainnya seperti keluarga, lingkungan, rumah singgah dan panti sosial. Ketiga, intervensi diarahkan untuk memberikan fasilitas pelayanan yang memadai, mencegah penyakit dan memberikan bantuan. Keempat, sasaran pekerja sosial medis adalah pasien, keluarga dan lingkungan masyarakat. Kelima, tujuan pekerja sosial medis adalah untuk meningkatkan kehidupan yang sehat, mencegah timbulnya berbagai penyakit serta memecahkan masalah sosial dan psikologis yang berkaitan dengan penyakit.

Pekerja sosial dalam melakukan penanganan terhadap pasien skizofrenia memiliki beberapa pendekatan intervensi seperti pendekatan bio-psiko-sosial-spiritual. Intervensi yang dilakukan pekerja sosial kepada pasien skizofrenia, menyesuaikan kondisi dan situasi pasien. Pekerja Sosial harus memiliki strategi dalam melakukan pendampingan terhadap pasien skizofrenia saat melakukan rehabilitasi sesuai tingkat penyakitnya, karena strategi yang digunakan akan mempengaruhi keberhasilan seorang pekerja sosial. Pasien skizofren yang telah mengalami masa rehabilitasi akan dikembalikan kepada keluarga dan masyarakat maka pasien akan mengalami masa adaptasi dengan lingkungannya. Peran pekerja sosial dalam mendampingi pasien skizofren pada saat rehabilitasi agar bisa membuat pasien skizofren menjadi lebih kuat dan menghargai diri sendiri 79 Copyright @ 2018, JKM, p-ISSN 2088-6098, e-ISSN 2550-0538 
sehingga dapat mencapai taraf kesembuhan yang lebih baik dan meningkatkan keberfungsian sosialnya secara utuh dengan menggunakan strategi pendampingan pekerja sosial. Akan tetapi realiatanya masih banyak pasien skizofren yang belum dapat menghargai diri sendiri dan belum bisa mencapai taraf kesembuhan yang lebih baik sehingga belum bisa meningkatkan keberfungsian sosialnya secara utuh di lingkungannya.

Terdapat beberapa studi tentang pekerja sosial dan gangguan jiwa. Studi- studi tersebut bisa dibagi menjadi beberapa kelompok yaitu: pertama, studi- studi tentang pekerja sosial dan gangguan jiwa yang berfokus terhadap intervensi yang diberikan, terdapat pada studi Meilanny Santoso Meilanny Santoso.(Santoso, Krisnani, \& Hadrasari, 2017) Selain Meilanny Santoso, studi lain yang membahas tetang intervensi pekerja sosial pada pasien gangguan jiwa dalam karya Fahri Alia yang membahas tentang bagaimana reunifikasi eks gangguan jiwa bagi korban perceraian melalui terapi behavioral theory.. (Alia, Wibowo, Sukendar, \& Dina, 2018)

Kedua, studi- studi tentang pekerja sosial dan gangguan jiwa yang berfokus terhadap terapi yang diberikan, terdapat pada studi Rika Damayanti. Rika Damayanti mengeksplorasi tentang pengaruh terapi suportif keluarga dalam merawat pasien gangguan jiwa.(Damayanti \& Hernawaty, 2014, hlm. 28)

Selain Rika Damayanti, studi lain yang membahas tetang terapi yang digunakan terhadap pasien gangguan jiwa dalam karya Endang Caturini S. Endang Caturini S, mengeksplorasi tentang bagaimana pengaruh cognitive Behavioral Therapy terhadap perubahan kecemasan dan mekanisme koping mampu meningkatkan harga diri pasien gangguan jiwa.(Caturini \& Handayani, 2014, hlm. 47) Ketiga, studi- studi tentang pekerja sosial dan gangguan jiwa yang berfokus terhadap dukungan sosial yang diberikan kepada pasien gangguan jiwa yang mencakup aspek psikologis, terdapat pada studi Syamsudin. Syamsudin mengeksplorasi tentang pengaruh dukungan sosial dalam gejala kekambuhan pasien gangguan jiwa.(Arifin, 1994) Selain Syamsudin, studi lain yang membahas tentang dukungan sosial dalam kemampuan berinteraksi bermasyarakat pada pasien gangguan jiwa dalam karya Lailatul Maghfiroh. Lailatul Maghfiroh, mengeksplorasi bahwasanya keluarga sangat berperan terhadap tingkat interaksi sosial bermasyarakat pada klien skizofrenia pasca perwatan.(Maghfiroh \& Khamida, 2015, hlm. 111) Selain itu adapun karya Kanti Fiona, yang mengeksplorasi tentang bahwasanya adanya pengaruh dukungan sosial terhadap kualitas hidup penderita skizofrenia (Fiona, 2013). 
Keempat, studi- studi tentang pekerja sosial dan gangguan jiwa yang berfokus terhadap strategi komunikasi pekerja sosial kepada pasien skizofrenia, yang terdapat pada studi Sugiyanto.(Sugiyanto, 2014) Selain Sugiyanto, studi lain yang membahas tentang strategi komunikasi pekerja sosial kepada pasien skizofrenia dalam karya Djoko Witojo. Djoko Witojo, mengeksplorasi bahwasanya strategi komunikasi terapetik bisa mengurangi perilaku kekerasan pada pasien skiofrenia..(Witojo \& Widodo, 2008) Kelima, studi- studi tentang pekerja sosial dan gangguan jiwa yang berfokus terhadap hubungan antara beban subjektif dengan kualitas hidup caregiver skizofrenia, yang terdapat pada studi Anisa Fitriani.

Berdasarkan, penelitian diatas kebanyak peneliti hanya berfokus terhadap bagaimana strategi komunikasi, terapi dan bagaimana dukungan sosial yang diberikan pasca rehabilitasi. Sedangkan penelitian ini lebih berfokus tentang bagaimana strategi yang digunakan pekerja sosial dalam mendampingi pasien gangguan jiwa pada masa rehabilitasi. Sehingga maka penulis tertarik untuk melakukan penelitian dengan judul "Strategi Pendampingan Pekerja Sosial Terhadap Pasien Skizofrenia Di Rumah Sakit Jiwa Grasia”.

\section{METODE PENELITIAN}

Penelitian ini menggunakan pendekatan deskriptif- kualitatif dengan mendeskripsikan dan menggambarkan fenomena-fenomena yang ada, baik bersifat alamiah maupun rekayasa manusia, yang lebih memperhatikan mengenai karakteristik, kualitas, keterkaitan antar kegiatan.(Nana Syaodih Sukmadinata, 2011, hlm. 73) Penelitian ini berfokus kepada strategi pendampingan pekerja sosial pada pasien gangguan jiwa di rumah sakit jiwa Ghrasia. Metode yang digunakaan dalam penelitian adalah observasi dan wawancara.(Nawari Ismail, 2015, hlm. 11) Metode partisipasi langsung yang dilakukan oleh peneliti dengan melihat secara langsung bagaimana strategi yang digunakan pendampingan pekerja sosial pada pasien skizofrenia di rumah sakit jiwa Ghrasia. Metode wawancara yang dilakukan oleh peneliti adalah dengan menggunakan metode wawancara secara mendalam yang akan dilakukan kepada narasumber yang terpilih yaitu pekerja sosial yang ada di rumah sakit Ghrasia.

Dalam subjek penelitian ini akan dilakukan secara purposive yaitu menyengaja memilih orang tertentu sesuai dengan kriteria yang dibutuhkan. Adapun yang akan menjadi subjek dalam penelitian ini memiliki kriteria tertentu diantaranya petugas pekerja sosial yang aktif melakukan kontak langsung dalam memberikan pendampingan terhadap pasien skizofrenia di rumah sakit Ghrasia 


\section{HASIL DAN PEMBAHASAN}

\section{Strategi Pendampingan Pekerja Sosial Pada Pasien Skizofrenia Di Rumah Sakit Jiwa} Ghrasia

Proses pelaksanaan yang dilakukan oleh pekerja sosial disetiap rumah sakit memiliki prosedur yang berbeda dalam aplikasiannya, misalnya dalam melakukan pendampingan kepada pasein skizofrenia, menggunakan beberapa strategi berbeda- beda sebagai pekerja sosial. Strategi yang dilakukan pekerja sosial dalam melakukan pendampingan terhadap kepada pasein skizofrenia, menyesuaikan kondisi dan situasi pasien sehingga tidak seluruh pasien mendapatkan pendampingan layanan yang sama dari seorang pekerja sosial. Informan menyatakan bahwa strategi yang digunakan pekerja sosial dalam melakukan pendampingan terhadap pasein skizofrenia menjadi salah satu proses dalam masa rehabilitasi mental, diantaranya sebagai berikut:(Wawancara bersama pekerja sosial di Rumah Sakit Jiwa Ghrasia, 2019)

1. Meningkatkan Pengetahuan (biopsikososial dan spiritual)

Meningkatan pengetahuan menjadi salah satu strategi yang digunakan pekerja sosial dalam mendampingi pasien skizofrenia, dengan menggunkan pendekatan biopsikososial. Biopsikososial merupakan alat untuk melakukan assessment, yang menekankan pengaruh intraktif dari faktor biologis, psikologis dan sosial terhadap perkembangan masalah-masalah remaja dan orang-orang yang berasal dari berbagai usia lainnya.(Roberts \& Gilbert, 2009) Spiritualitas pada hakikatnya adalah suatu kekuatan yang datang dari luar kekuatan diri sebagai manusia. Spiritual adalah pencarian manusia akan makna dan tujuan hidup, sehingga memiliki keseluruhan kepribadian dari sejumlah pengalaman hidup yang beragam . Selain itu, spiritual juga berkaitan dengan aspek etika, moral dan nilai.(Ariefuzzaman \& Fuaida, 2011) Salah satu contoh biopsikososial dan spiritual yang dapat digunakan oleh pekerja sosial dalam menangani kasus pasien skizofrenia diantaranya yaitu:(Wawancara bersama pekerja sosial di Rumah Sakit Jiwa Ghrasia, 2019)

a. Bio

Bio adalah yang berpengaruh pada pemenuhan kebutuhan dasar manusia dan adanya perubahan dari gambaran fisik, penampilan, dan status kesehatan. Menurut pekerja sosial salah satu contoh dari bio yaitu pertama, ketika memberikan edukasi tentang pentingnya kebersihan diri dan lingkungan, pasien skizofrenia diberikan contoh dan tuntun dalam melakukan proses tersebut dimulai dari pengarahan bahwasanya pasien tersebut wajib untuk membersihakan dirinya (mandi) dengan menggunakan sabun, shampo, dan air untuk 
membilas bersih dirinya. Kedua, pekerja sosial memberikan edukasi kepada pasien gangguan jiwa bahwasanya mereka di ajarkan untuk merapikan dan menyusun tempat tidurnya.

b. Psiko

Psiko adalah hal yang membahas gambaran tentang kondisi emosi klien, Kesehatan jiwa, Catatan menjadi korban. Menurut pekerja sosial salah satu contoh dari psiko yaitu saat terapi kelompok, yang mana pasien skizofrenia saat terapi kelompok tidak terfokus dan avuh terhadap kondisi disekitarnya. Menjadi apatis terhadap lingkungan disekitarnya.

c. Sosial

Sosial adalah hal yang membahas gambaran tentang Situasi saat ini dan sejarah perpindahan, Pekerjaan dan status keuangan, Hubungan dan peran dalam keluarga, Keberfungsian sekolah dan keberfungsian dari institusi lainnya (jika masih bersekolah). Menurut pekerja sosial salah satu contoh dari sosial yaitu tentang edukasi bahwasanya pasien tidak boleh mengambil barang atau makanan orang lain tanpa meminta izin terlebih dahulu.

d. Spiritual

Spiritual adalah hal yang membahas gambaran tentang data spiritual dan budaya, Menurut pekerja sosial salah satu contoh dari spiritual yaitu tentang edukasi yang diberikan oleh pekerja sosial dengan menghadirkan penyuluh agama untuk membahas tentang materi yang berkitan dengan keihklasan. Akan tetapi materi yang disajikan pun dengan menggunakan bahasa yang mudah dipahami.

\section{Meningkatkan Kesadaran Pasien Skizofrenia}

Meningkatkan kesadaran menjadi hal yang dibutuhkan dalam melakukan peningkatan kapasitas dalam diri pasien skizofrenia. Pada tahapan pendampingan pekerja sosial mampu membuat perubahan untuk merubah kondisi yang lebih baik bagi pasien skizofrenia. Apabila skizofrenia bisa meningkatkan kesadaran di dalam dirinya maka akan terjadi perubahan perilaku dalam kehidupan sehari- harinya.

Menurut pendapat informan (pekerja sosial) menyatakan bahwa dalam meningkatkan kesadaran pasien ganngguan jiwa salah satunya adalah dengan mengikuti kegiatan terapi kelompok, yang akan membuat pasien tersebut akan lebih berkonsentrasi, lebih aktif dalam beraktivitas serta terjalinnya konunikasi yang baik antara pasien. (Wawancara bersama pekerja sosial di Rumah Sakit Jiwa Ghrasia, 2019) 
Terapi kelompok yang di berikan terdiri atas 3 sesi yang pertama adalah pertama pemanasan, pemanasan yang dimaksud disini dimulai dari pekenalan dari pekeja sosial sampai kepada pasien yang ada didalam ruangan tersebut. Setiap pasien yang memperkenalkan dirinya harus menyebutkan nama serta alamat asalnya, hal ini berguna untuk mempermudah antara pasien satu dengan yang lainnya mengingat perkenalan terseut. Kedua kegiatan inti, aktivitas yang dilakukan pasien disini misalnya pasien ingin menyanyanyi. Aktivitas menayanyipun memiliki ketentuan tertentu yang telah ditentukan oleh pekerja sosial yaitu setiap pasien yang menyanyi harus secara ekstafet agar menguji konsentrasi pasien anatara satu dengan yang lainnya, disnilah pekerja sosial bisa melihat bagaimna pemahaman pasien tenatng instruksi yang diberikan mudah dipahami atau tidak, dan di sini akan terlihat siapa saja pasien yang memiliki konsentrasi yang kurang fokus. Ketiga, Pendinginan atau evaluasi, disini pasien yang mengikuti seluruh aktifitas kelompok tersebut di harapkan mampu mengingat dan menyebutkan rangkaian kegiatan apa saja yang dilakukan sepanjang sesi terapi kelompok yang telah dilaksanakan, pasien di haraokan mampu menginagt siapa saja nama di dalam anggota kelompoknya tersebut. (Wawancara bersama pekerja sosial di Rumah Sakit Jiwa Ghrasia, 2019)

\section{Meningkatkan Kemampuan Dan Keterampilan Pasien Skizofrenia}

Meningkatkan kemampuan dan keterampilan menjadi salah satu strategi pendampingan yang dilakukan oleh pekerja sosial. Kemampuan yang dimiliki oleh skizofrenia akan di representasikan melaui pemberian keterampilan. Keterampilan yang diberikan oleh pekerja sosial berupa pendampingan latihan kerja. Tugas pekerja sosial dalam pendampingan latihan kerja adalah membangkitkan aktivitas positif pasien melalui aktivitas dan meningkatkan kembali daya konsentrasi ingatan pasien serta motivasi melalui berbagai kegiatan yang sesuai dengan diri pasien, yang bertujuan untuk mengevaluasi perkembangan tingkah laku pasien secara teratur dan berkelanjutan. Mengetahui efek terapi yang diberikan kepada pasien ketika mengatasi masalah untuk memenuhi kebutuhan hidupnya.

Pekerja sosial menyatakan bahwa ada beberapa hal yang dilakuakan oleh pekerja sosial dalam menigkatkan kesadaran skizofrenia dalam proses rehabilitasi misalnya pasien diajarkan tentang latihan kerja, Bentuk-bentuk latihan kerja yang diajarkan antara lain membuat telur asin, membuat aneka kue/snack, membuat keraiinan tangan dari sedotan, dan menyulam biasanya hal ini dilakuakn oleh pasein putri. Sedangkan Pasien 
putera biasanya diajarkan tentang pertanian tanaman hias dan cara menanam sayuran sampai kepada menjual hasil pertaniannya kepada orang- orang yang ada dirumah sakit dan pertukangan membuat batako.

Berdasarkan ketiga strategi pendampingan yang dilakukan oleh pekerja sosial dalam meningkatkan pengetahuan pasien skizofrenia dilakukan secara berulang- ulang selama masa rehabilitasi, untuk ketentuan waktu keberadaan pasien gangguan jiwa di rumah sakit Grasia adalah maksimal 1 bulan. Saat pekerja sosial melakukan pendampingan kepaada pasien skizofrenia pada masa rehabilitasi tidak melibatkan peran keluarga, karena pada masa rehabilitasi hanya berfokus terhadap rumah sakit saja.

\section{Faktor Pendukung Dan Penghambat Dalam Pendampingan Pekerja Sosial Pada Pasien Skizofrenia Di Rumah Sakit Jiwa Ghrasia}

Menurut pendapat informan (pekerja sosial) menyatakan bahwa Faktor pendukung dalam melakukan pendampingan pekerja sosial terletak pada dua aspek yaitu pasien dan keluarga. Apabila pasien mau mengikuti seluruh kegiatan yang direncanakan oleh pekerja sosial maka strategi pendampingan yang digunakanpun akan berjalan secara efektif. Sedangkan keluarga juga bisa menjadi faktor pendukung ketika keluarga sering membesuk pasien ke rumah sakit jiwa maka pasien akan merasakan danya dukungan dan kekuatan yang tercipta antara keluarga dan pasien sehingga pasien tersebut semangat dalam melakukan rangkaian yang ada di rumah sakit jiwa . (Wawancara bersama pekerja sosial di Rumah Sakit Jiwa Ghrasia, 2019)

Faktor penghambat pekerja sosial terletak pada beberapa aspek, diantaranya: pertama ketika pasien mengalami kejenuhan, maka mereka akan lebih sulit diarahkan. Karena perkembangan emosi dan psikologis pasien perwaktu, dan itu juga akan memepengaruhi pasien yang lainnya sehingga tidak mudah terkontrol. Kedua, ketika banyak bagian aktifitas dari yang di lakukan, maka kemungkinan mereka tidak mengikuti aktivitas tersebut secara runtun. Pasien gangguan jiwa suka berpindah- pindah dalam melakukan aktivitas, misalnya seorang pasien seharusnya fokus di bagain aktivitas pertanian akan tetapi pasien langsung pindah dan kabur kebagian aktivitas yang lainnya misalnya pertukangan. Padahal idealnya aktivitas yang dilakukan pasien setiap harinya hanya berfokus tehadap satu aktivitas saja.

Ketiga, ketika pasien tidak merasa cocok dengan pasien yang lainnya dan juga pekerja sosial yang ada akan berpengaruh terhadap seluruh kegiatan pendampingan yang akan diberikan. pasien cenderung akan marah- marah dan tidak mau mengikuti rangkaian apa saja yang sudah 
diataur oleh pekerja sosial. Keempat, keluarga yang jarang membesuk menjadi salah satu pengahmbat yang cukup signifikan dalam kesembuhan pasien. Ketika pasien yang awalnya sudah selesai mengikuti seluruh kegiatan yang diberikan oleh pekerja sosial dan dinyatakan sembuh oleh dokter da perawat yang ada dan tinggal menunggu keluarga yang membesuk untuk membawa pulang kerumah. Akan tetapi keluarga, yang tidak membesuk dan kelurga yang tidak tepat waktu ketika melakukan penjemputannya lama aan membuat pasien akan kambuh lagi keadaan psikologisnya. Dan ketika kekambuhan itu terjadi maka akan semakin susah untuk melakuakn rangkaian aktivitas yag lainnya.(Wawancara bersama pekerja sosial di Rumah Sakit Jiwa Ghrasia, 2019)

\section{KESIMPULAN}

Strategi yang digunakan pekerja sosial dalam melakukan pendampingan terhadap pasien gangguan jiwa menjadi salah satu proses dalam masa rehabilitasi mental, diantaranya yaitu: pertama, meningkatkan pengetahuan yaitu menggunakan pendekatan biopsikososial dan spiritual; kedua, meningkatkan kesadaran; ketiga, meningkatkan kemampuan dan keterampilan. Selain itu faktor pendukung dan penghambat dalam pendampingan pekerja sosial pada pasien gangguan jiwa di rumah sakit jiwa Ghrasia berasal dari pasien dan keluarga pasien itu sendiri.

\section{DAFTAR PUSTAKA}

Alia, F., Wibowo, T. S. A., Sukendar, H. B., \& Dina, E. L. (2018). Intervensi Pekerja Sosial Dalam Reunifikasi Eks Gangguan Jiwa Di Balai Rehabilitasi Sosial Bina Karya Dan Laras (BRSBKL) Yogyakarta. Welfare: Jurnal Ilmu Kesejahteraan Sosial. 1(1).

Ariefuzzaman, S. N., \& Fuaida, L. D. (2011). Belajar Teori Pekerjaan Sosial. Ciputat: Lembaga Penelitian UIN Syarif Hidayatullah Jakarta.

Ashturkar, M. D., \& Dixit, J. V. (2013). Selected Epidemiological Aspects of Schizophrenia: Across Sectional Study At Terityary Care Hospital Maharashra. National Journal of Community Medicine, 65-69.

Badan Penelitian dan Pengembangan Depkes RI. (2007). Laporan Hasil Riset Kesehatan Dasar (RISKESDAS) Nasional 2007. Jakarta.

Ballard, K. A., Kennedy, W. Z., \& O’Brien, P. G. (2014). Keperawatan Kesehatan Jiwa Psikiatrik: Teori \& Praktik. Jakarta: EGC.

Barker, R. L. (1995). The Social Work Dictionary. Washington DC: NASW Press

Caturini, E., \& Handayani, S. (2014). Pengaruh Cognitive Behavioral Therapy (CBT) terhadap Perubahan Kecemasan, Mekanisme Koping, Harga Diri pada Pasien Gangguan Jiwa dengan Skizofrenia di RSJD Surakarta. Jurnal terpadu ilmu kesehatan. Politeknik Kesehatan Surakarta. Interest: Jurnal Ilmu Kesehatan, 3(1).

Damayanti, R., \& Hernawaty, T. (2014). Pengaruh Terapi Suportif Keluarga Terhadap Kemampuan Keluarga Merawat Klien Gangguan Jiwa di Kecamatan Bogor Timur. KONSELI: Jurnal Bimbingan dan Konseling (E-Journal), 1(1), 22-32. 
DEPKES. (t.t.). Diambil dari http://www.depkes.go.id/article/print/16100700005/perankeluarga-dukung-kesehatan-jiwa-masyarakat

Fiona, K. (2013). Pengaruh Dukungan Sosial Terhadap Kualitas Hidup Penderita Skizofrenia. Jurnal Psikologi Kepribadian dan Sosial Universitas Airlangga, 2(3), 106-13.

Gelder, M., Gath, D., \& Mayou, R. (1989). Oxford textbook of psychiatry. Oxford university press.

Hawari, D. (2009). Pendekatan Holistik Pada Gangguan Jiwa Edisi 2. Jakarta: FKUI.

Ismail, Nawari. (2015). Metodologi Penelitian Untuk Studi Islam. Yogyakarta: Penerbit Samudra Biru.

Kiran, C., \& Chaudhury, S. (2009). Understanding delusions. Industrial psychiatry journal, 18(1), 3 .

Maghfiroh, L., \& Khamida, K. (2015). Peran Keluarga dalam Peningkatan Kemampuan Interaksi Sosial Bermasyarakat Klien Skizofrenia Pasca Perawatan di Rumah Sakit. Jurnal Ilmiah Kesehatan (Journal of Health Sciences), 8(1).

Maslim, R. (2001). Buku Saku Diagnosis Gangguan Jiwa Rujukan Ringkas Dari PPDGJIII. Jakarta: Bagian Ilmu Kedokteran Jiwa FK Unika Atma Jaya.

Paolini, E., Moretti, P., \& Compton, M. T. (2016). Delusions In First-Episode Psychosis: Principal Component Analysis Of Twelve Types Of Delusions And Demographic And Clinical Correlates Of Resulting Domains. Psychiatry research, 243, 5-13.

Roberts, A. R., \& Gilbert, J. (2009). Buku Pintar Pekerja Sosial. BPK Gunung Mulia. Rochman, Kholil. 2013. Kesehatan Mental. Purwokerto: STAIN Press.

Santoso, M. B., Krisnani, H., \& Hadrasari, I. (2017). Intervensi Pekerja Sosial Terhadap Orang Dengan Skizofrenia. Share: Social Work Journal, 7(2), 1-9.

Sugiyanto, S. (2014). Strategi Komunikasi Pekerja Sosial dengan Pasien Skizofrenia dalam Proses Rehabilitasi Studi di Rumah Sakit Jiwa Dr. Soeroyo Magelang Jawa Tengah. Share: Social Work Journal, 4(1).

Sukmadinata, N. S. (2011). Metode Penelitian Pendidikan Pendekatan Kuantitatif, Kualitatif dan R\&D. Cetakan, 11, 23-26.

Undang-Undang, R. I. (2014). Nomor 18 Tahun 2014. Tentang kesehatan Jiwa, Presiden Republik Indonesia, Jakarta.

Wawancara bersama pekerja sosial di Rumah Sakit Jiwa Ghrasia. (2019, April 27).

Witojo, D., \& Widodo, A. (2008). Pengaruh Komunikasi Terapeutik Terhadap Penurunan Tingkat Perilaku Kekerasan Pada Pasien Skizofrenia Di Rumah Sakit Sakit Jiwa Daerah Surakarta. 1(4). 